\title{
Occurrence and Phenotypes of Pyrimethanil Resistance in Penicillium expansum from Apple in Washington State
}

R. Caiazzo, Washington State University, Tree Fruit Research and Extension Center, Wenatchee; Y. K. Kim, Pace International, Wapato, WA; and C. L. Xiao, United States Department of Agriculture-Agricultural Research Service, San Joaquin Valley Agricultural Sciences Center, Parlier, CA

\begin{abstract}
Caiazzo, R., Kim, Y. K., and Xiao, C. L. 2014. Occurrence and phenotypes of pyrimethanil resistance in Penicillium expansum from apple in Washington State. Plant Dis. 98:924-928.

Penicillium expansum is the cause of blue mold in stored apple fruit. In 2010-11, 779 isolates of $P$. expansum were collected from decayed apple fruit from five packinghouses, tested for resistance to the postharvest fungicide pyrimethanil, and phenotyped based on the level of resistance. In 2010, 85 and $7 \%$ of the isolates were resistant to pyrimethanil in packinghouse A and B, respectively, where pyrimethanil had been used for four to five consecutive years. In 2011, pyrimethanil or fludioxonil was used in packinghouse A, and $96 \%$ of the isolates from the fruit treated with pyrimethanil were resistant but only $4 \%$ of the isolates from the fruit treated with fludioxonil were resistant to pyrimethanil, suggesting that fungicide rotation substantially reduced the

lates were detected in 2010 in the three other packinghouses where the fungicide had been used recently on a small scale. However $1.8 \%$ of the isolates from one of the three packinghouses in 2011 were resistant to pyrimethanil. A significantly higher percentage of thiabendazoleresistant than thiabendazole-sensitive isolates were resistant to pyrimethanil. Of the pyrimethanil-resistant isolates, 37 to 52,4 to 5 , and 44 to $58 \%$ were phenotyped as having low, moderate, and high resistance to pyrimethanil, respectively. Fludioxonil effectively controlled pyrimethanil-resistant phenotypes on apple fruit but pyrimethanil failed to control phenotypes with moderate or high resistance to pyrimethanil and only partially controlled the low-resistance phenotype.
\end{abstract} frequency of pyrimethanil resistance. No pyrimethanil-resistant iso-
Apple cultivars differ in time to maturity. In Washington State, apple harvest starts in mid-August and may not finish until early November, depending on the cultivar. At harvest, apple fruit are hand picked and placed into wooden or plastic storage bins (approximately $400 \mathrm{~kg} / \mathrm{bin}$ ), which are then transported to storage and packing facilities. Fruit may be packed shortly after harvest. Because of a large volume of fruit to be packed and marketed, fruit may be stored in cold rooms for an extended period of up to 12 months. Postharvest fruit rot diseases may develop on fruit in storage bins prior to packing or on the fruit in the containers after packing.

Penicillium expansum (Link) Thom is the cause of blue mold, a major postharvest disease of apple (17). Conidia are the main type of inoculum of $P$. expansum responsible for fruit infection leading to blue mold in stored apple fruit. Conidia of $P$. expansum are present in the orchards, storage bins, fruit storage rooms, dump-tank and flotation-tank water, and packing facilities $(17,20)$ but conidia surviving on storage bins are believed to be the most important source of inoculum contributing to selection for resistance to postharvest fungicides because storage bins cycle survived conidia of $P$. expansum from year to year and the same populations are exposed to postharvest fungicides every year when postharvest fungicide drenches are implemented (17). P. expansum invades apple fruit primarily through wounds on the fruit skin, such as punctures and bruises that occur at harvest or during postharvest handling

Corresponding author: C. L. Xiao, E-mail: Chang-Lin.Xiao@ars.usda.gov

Mention of trade names or commercial products in this article is solely for the purpose of providing specific information and does not imply recommendations or endorsement by the United States Department of Agriculture (USDA). USDA is an equal opportunity provider and employer.

Accepted for publication 21 January 2014.

http://dx.doi.org/10.1094/PDIS-07-13-0721-RE

This article is in the public domain and not copyrightable. It may be freely reprinted with customary crediting of the source. The American Phytopathological Society, 2014.
(17). Protecting wounds from infections by $P$. expansum is essential to blue mold control. To reduce losses of fruit caused by blue mold and other postharvest diseases, a postharvest fungicide drench is commonly applied to the fruit prior to storage via recirculating drench solutions $(3,21)$. Prior to 2005 , thiabendazole (TBZ) was the most commonly used postharvest fungicide on apple and pear in the United States since the early 1970s, but intensive and exclusive postharvest use of benzimidazoles resulted in the development of TBZ resistance in $P$. expansum, leading to the failure of blue mold control $(4,12)$. In 2004, two new fungicides, fludioxonil and pyrimethanil, were registered for postharvest use on pome fruit in the United States. Both fungicides are highly effective in controlling blue mold and some other major postharvest diseases of apple and have since been used increasingly on apple $(4,19,21)$. However, pyrimethanil resistance was detected for the first time in 2009 (reported in 2011) in P. expansum from decayed apple fruit at a packinghouse where pyrimethanil had been used annually as a postharvest drench treatment; however, the resistance frequency was low $(<1 \% ; 22)$. P. expansum is considered a highrisk pathogen for the development of fungicide resistance (2).

Pyrimethanil belongs to the anilinopyrimidine class, which is believed to inhibit biosynthesis of methionine and other amino acids and the secretion of hydrolytic enzymes involved in the infection process of Botrytis cinerea and other fungal pathogens (5). Anilinopyrimidines are considered medium-risk fungicides in the development of fungicide resistance in fungal pathogens (6). Resistance to anilinopyrimidine fungicides has been reported in field isolates of $B$. cinerea from many crops $(1,9,15)$ and in Venturia inaequalis from apple (6). Different phenotypes of anilinopyrimidine resistance in $B$. cinerea have been detected, with resistance levels ranging from low to very high $(9,15)$. Currently, little is known about pyrimethanil resistance in $P$. expansum from apple.

The objectives of the present study were to (i) monitor pyrimethanil resistance in $P$. expansum collected from decayed apple fruit at commercial apple packinghouses in Washington State, (ii) phenotype pyrimethanil resistance in $P$. expansum, and (iii) evaluate other registered postharvest fungicides for control of pyrimethanilresistant phenotypes of $P$. expansum on apple fruit. 


\section{Materials and Methods}

Collection of $\boldsymbol{P}$. expansum isolates. Surveys for pyrimethanil resistance in $P$. expansum were conducted in 2010 and 2011 at five commercial fruit packinghouses in central Washington, which is the primary region for apple production in the state (Table 1). The five packinghouses were designated as packinghouses A, B, C, D, and $\mathrm{E}$. At packinghouses $\mathrm{A}$ and $\mathrm{B}$, pyrimethanil had been used annually since 2005 as a postharvest drench treatment before apple fruit were placed in cold storage whereas, at packinghouses C, D, and $\mathrm{E}$, neither pyrimethanil nor fludioxonil had been used on a large scale prior to 2009. The fruit that were sampled for survey of pyrimethanil resistance in this study had been drenched prior to storage with either pyrimethanil as Penbotec 400SC (Janssen Pharmaceutical N.V.) or fludioxonil as Scholar 50WP or Scholar 230SC (Syngenta Crop Protection), and the fungicide drench treatments were applied as a standard decay control program for a given year implemented by the packinghouse (Table 1). At these five packinghouses, apple fruit were typically stored in either regular or controlled atmosphere ( 1 to $2 \% \mathrm{O}_{2}$ and $0.5 \% \mathrm{CO}_{2}$ ) at -1 to $3^{\circ} \mathrm{C}$.

During April to August 2010 and 2011, decayed apple fruit with blue mold or blue mold-like symptoms were collected during presizing or packing operations at the packinghouses. At the time that decayed fruit were collected, the fruit had been stored for several months after harvest, depending on cultivars (i.e., the fruit sampled during April to August 2010 and 2011 were the crops produced in the 2009 and 2010 seasons, respectively). Apple cultivars with decayed fruit collected during this study included 'Gala', 'Red Delicious', 'Braeburn', 'Fuji', and 'Pink Lady'. Decayed apple fruit were sampled from two, five, five, four, and two grower lots (each grower lot represents an orchard) in 2010 and five, three, six, two, and two grower lots in 2011 at packinghouses A, B, C, D, and E, respectively. Each lot was sampled only once.

To isolate Penicillium spp. from decayed fruit, the peel at the margin of the decayed area was removed and small pieces of decayed tissue were placed on an acidified potato dextrose agar (APDA; $4 \mathrm{ml}$ of a $25 \%$ [vol/vol] solution of lactic acid per liter of medium) plate. Cultures were transferred onto fresh APDA plates. Isolates of Penicillium spp. were identified as $P$. expansum following Pitt's protocol and description of the fungus using three different media (16). Isolates of $P$. expansum used in this study were single-spored and stored as conidial suspensions in $15 \%$ glycerol $(1: 1, \mathrm{vol} / \mathrm{vol})$ at $-80^{\circ} \mathrm{C}$. In total, 389 and 390 isolates of $P$. expansum were obtained from decayed fruit in 2010 and 2011, respectively (Table 1).

Screening for resistance to pyrimethanil, TBZ, and fludioxonil. Because the primary focus of this study was to monitor pyrimethanil resistance, all isolates of $P$. expansum were screened for resistance to pyrimethanil. Sensitivity to pyrimethanil was tested on an agar medium ( $10 \mathrm{~g}$ of glucose, $2 \mathrm{~g}$ of $\mathrm{K}_{2} \mathrm{HPO}_{4}, 2 \mathrm{~g}$ of $\mathrm{KH}_{2} \mathrm{PO}_{4}$, and $12.5 \mathrm{~g}$ of agar; 11) amended with pyrimethanil $(96 \%$ a.i.; Janssen Pharmaceutica) at 0.0 or $0.5 \mu \mathrm{g} / \mathrm{ml}$, which is the minimum inhibitory concentration and was suggested as a discriminatory concentration for pyrimethanil resistance, using a conidial germination assay (12). Conidial suspensions (approximately $10^{5}$ conidia/ml) were made from 7 - to 10 -day-old potato dextrose agar (PDA) cultures and $100 \mu \mathrm{l}$ was spread on the fungicide-amended medium. Cultures were incubated at $20^{\circ} \mathrm{C}$ for $40 \mathrm{~h}$. The percentage of conidial germination (100 to 200 conidia from each treatment were examined) was assessed microscopically. A conidium was considered germinated if the germ tube was at least twice its length. Isolates that were able to germinate with pyrimethanil at $0.5 \mu \mathrm{g} / \mathrm{ml}$ were considered resistant to pyrimethanil $(12,22)$.

In conjunction with testing for resistance to pyrimethanil, all isolates also were tested for resistance to the two other apple-postharvest fungicides, TBZ and fludioxonil. Technical-grade TBZ (99\% a.i.; Sigma-Aldrich) was dissolved in methanol to prepare PDA amended with TBZ at $5 \mu \mathrm{g} / \mathrm{ml}$. Dry conidia were transferred from a 7-day-old PDA culture to sterile distilled water with $0.01 \%$ Tween 20 (18) to prepare a suspension of about $10^{6}$ conidia/ml. The conidial suspension was poured into $16 \mathrm{ml}$ of molten PDA at $50^{\circ} \mathrm{C}$, and the medium was poured immediately into a plate. Cultures were incubated at $20^{\circ} \mathrm{C}$ for $24 \mathrm{~h}$. Agar plugs were aseptically cut from the cultures with a 6-mm-diameter cork borer. Three such plugs were placed upside-down on TBZ-amended PDA in each plate. Three replicate plates were used for each isolate. Colony diameters were measured after 5 days at $20^{\circ} \mathrm{C}$. Isolates that were able to grow on the TBZ-amended PDA at $5 \mu \mathrm{g} / \mathrm{ml}$ were considered resistant to TBZ.

Technical-grade fludioxonil (93\% a.i.; Syngenta Crop Protection) was dissolved in acetone and used to prepare PDA amended with fludioxonil at $0.5 \mu \mathrm{g} / \mathrm{ml}$, which was suggested as a discriminatory concentration for fludioxonil resistance (12). Inoculum was prepared as described above. A 6-mm-diameter agar plug was placed at the center of each plate containing a fungicide-amended medium, and there were three replicates per isolate. The radial growth (colony diameter) of each isolate was measured after incubation for 7 days at $20^{\circ} \mathrm{C}$ in the dark. Isolates able to grow on the amended medium with fludioxonil at $0.5 \mu \mathrm{g} / \mathrm{ml}$ were considered resistant (12). All tests for each isolate were performed twice.

A $\chi^{2}$ test using SAS PROC FREQ (version 9.2; SAS Institute, Inc.) was performed to determine whether the percentage of TBZresistant isolates that developed resistance to pyrimethanil was significantly higher than that of TBZ-sensitive isolates.

Phenotypes of pyrimethanil-resistant isolates. Pyrimethanilresistant isolates were further classified into different resistant phenotypes using the conidial germination assay described above at four concentrations of pyrimethanil $(0.0,0.5,10$, and $40 \mu \mathrm{g} / \mathrm{ml})$. The percentage of conidial germination at different concentrations of the fungicide was determined after incubation at $20^{\circ} \mathrm{C}$ for $40 \mathrm{~h}$, as described above. An isolate was classified as having low resistance to pyrimethanil if conidia germinated with pyrimethanil at

Table 1. Frequency of pyrimethanil-resistant isolates of Penicillium expansum from apple fruit collected in 2010 and $2011^{\mathrm{y}}$

\begin{tabular}{|c|c|c|c|c|c|c|c|c|}
\hline \multirow[b]{3}{*}{$\mathbf{P H}^{\mathbf{z}}$} & \multirow[b]{3}{*}{ Drench } & \multicolumn{3}{|c|}{2010} & \multicolumn{4}{|c|}{2011} \\
\hline & & & \multicolumn{2}{|c|}{ Frequency of resistance $(\%)$} & \multirow[b]{2}{*}{ Drench } & \multirow[b]{2}{*}{$N$} & \multicolumn{2}{|c|}{ Frequency of resistance $(\%)$} \\
\hline & & $N$ & Thiabendazole & Pyrimethanil & & & Thiabendazole & Pyrimethanil \\
\hline \multirow[t]{2}{*}{$\overline{\mathrm{A}}$} & Pyrimethanil & 177 & 85.9 & 84.7 & Fludioxonil & 47 & 12.8 & 4.2 \\
\hline & na & na & na & na & Pyrimethanil & 118 & 97.4 & 95.8 \\
\hline B & Pyrimethanil & 129 & 10.8 & 7 & Fludioxonil & 99 & 7 & 1 \\
\hline $\mathrm{C}$ & Pyrimethanil & 26 & 7.7 & 0 & Pyrimethanil & 55 & 5.4 & 1.8 \\
\hline $\mathrm{D}$ & Pyrimethanil & 29 & 55.2 & 0 & Fludioxonil & 31 & 3.2 & 0 \\
\hline $\mathrm{E}$ & Pyrimethanil & 28 & 3.6 & 0 & Pyrimethanil & 40 & 2.5 & 0 \\
\hline
\end{tabular}

y The drench treatment (Drench) was applied to the fruit on the same day of harvest during mid-August to early November, depending on apple cultivars, while isolates were obtained from decayed apple fruit collected during April to August the following years. Decayed fruit with blue mold or blue mold-like symptoms were collected during presizing or packing operations after the fruit had been stored for several months after harvest. Apple cultivars with decayed fruit collected during this study included 'Gala', 'Red Delicious', 'Braeburn', 'Fuji', and 'Pink Lady'. $N=$ number of isolates and na = not applicable.

${ }^{\mathrm{z}}$ At packinghouses $(\mathrm{PH}) \mathrm{A}$ and $\mathrm{B}$, pyrimethanil had been used as a prestorage drench treatment each year for 4 to 5 years prior to 2009 whereas, at packinghouses C, D, and E, neither pyrimethanil nor fludioxonil had been used at a large scale prior to 2009. 
0.5 but not at $10 \mu \mathrm{g} / \mathrm{ml}$, moderate resistance to pyrimethanil if conidia germinated at 10 but not at $40 \mu \mathrm{g} / \mathrm{ml}$, and high resistance to pyrimethanil if conidia germinated at $40 \mu \mathrm{g} / \mathrm{ml}$.

Efficacy of postharvest fungicides in controlling blue mold on apple fruit incited by pyrimethanil-resistant phenotypes. Organic Red Delicious apple fruit purchased from a local fruit packinghouse were used in the study. Fruit were surface-disinfested in $0.6 \%$ sodium hypochlorite solution for $5 \mathrm{~min}$, rinsed three times with deionized water, and air dried. Prior to inoculation, fruit were kept at room temperature $\left(21\right.$ to $\left.25^{\circ} \mathrm{C}\right)$ overnight.

Five $P$. expansum isolates representing different phenotypes of resistance to pyrimethanil and TBZ, including an isolate sensitive to both TBZ and pyrimethanil, were included in the test, and all five isolates were sensitive to fludioxonil (Table 2). Conidial suspensions $\left(1 \times 10^{4}\right.$ conidia/ml $)$ made from 7-day-old PDA cultures grown at $20^{\circ} \mathrm{C}$ were used as inoculum for fruit inoculation. Each apple fruit was wounded with a 4-mm-diameter finish-nail head to $3 \mathrm{~mm}$ in depth and inoculated by delivering $20 \mu \mathrm{l}$ of the conidial suspension into the wound with a pipette. At approximately $50 \mathrm{~min}$ after inoculation, apple fruit were dipped for $30 \mathrm{~s}$ in either water as controls or in one of the two following fungicide solutions: pyrimethanil applied as Penbotec 400SC (Janssen Pharmaceutica) at $1.25 \mathrm{ml} /$ liter and fludioxonil applied as Scholar 230SC (Syngenta Crop Protection) at $0.94 \mathrm{ml} /$ liter. Fruit were allowed to air-dry for $15 \mathrm{~min}$ after dipping and then placed in fruit trays and stored in cardboard boxes at $0^{\circ} \mathrm{C}$ for 12 weeks. Each treatment had three replicate trays each with 20 fruit. Fruit were considered decayed when a visible lesion developed at the inoculation site on the fruit. Lesion diameters were measured and percent fruit with decay symptoms was calculated. The experiment was performed twice. The differences among treatments were analyzed by analysis of variance using PROC GLM of SAS and means were separated by the Waller-Duncan K-ratio $t$ test. Disease incidence data were arcsine-transformed prior to analysis (7).

\section{Results}

Frequency of pyrimethanil-resistant phenotypes in $\boldsymbol{P}$. expansum. In total, 389 and 390 isolates of $P$. expansum were obtained

Table 2. Efficacy of postharvest fungicides for the control of blue mold incited by different fungicide-resistant phenotypes of Penicillium expansum on 'Red Delicious' apple fruit after 12 weeks of storage at $0^{\circ} \mathrm{C}^{\mathrm{x}}$

\begin{tabular}{|c|c|c|c|c|}
\hline Isolate & Phenotype ${ }^{y}$ & Treatment $^{\mathrm{z}}$ & $\begin{array}{c}\text { Incidence } \\
(\%)\end{array}$ & $\begin{array}{l}\text { Lesion diameter } \\
(\mathbf{m m})\end{array}$ \\
\hline \multirow[t]{3}{*}{ CLX8841 } & $\mathrm{TBZ}^{\mathrm{R}} \mathrm{Flu}^{\mathrm{S}} \mathrm{Pyr}^{\mathrm{HR}}$ & Nontreated & $95 \mathrm{a}$ & $28.4 \mathrm{a}$ \\
\hline & & Pyrimethanil & $93.3 \mathrm{a}$ & $26.8 \mathrm{a}$ \\
\hline & & Fludioxonil & $0 \mathrm{~b}$ & $0 \mathrm{~b}$ \\
\hline \multirow[t]{3}{*}{ CLX8818 } & $\mathrm{TBZ}^{\mathrm{R}} \mathrm{Flu}^{\mathrm{S}} \mathrm{Pyr}^{\mathrm{MR}}$ & Nontreated & $98.3 \mathrm{a}$ & $32.43 \mathrm{a}$ \\
\hline & & Pyrimethanil & $92.5 \mathrm{~b}$ & $26.7 \mathrm{a}$ \\
\hline & & Fludioxonil & $0 \mathrm{c}$ & $0 \mathrm{~b}$ \\
\hline \multirow[t]{3}{*}{ CLX8873 } & $\mathrm{TBZ}^{\mathrm{R}} \mathrm{Flu}^{\mathrm{S}} \mathrm{Pyr}^{\mathrm{LR}}$ & Nontreated & $95 \mathrm{a}$ & $29.2 \mathrm{a}$ \\
\hline & & Pyrimethanil & $68 \mathrm{~b}$ & $24.6 \mathrm{a}$ \\
\hline & & Fludioxonil & $0 \mathrm{c}$ & $0 \mathrm{~b}$ \\
\hline \multirow{3}{*}{ CLX8391 } & $\mathrm{TBZ}^{\mathrm{R}} \mathrm{Flu}^{\mathrm{S}} \mathrm{Pyr}^{\mathrm{S}}$ & Nontreated & $98 \mathrm{a}$ & $31.1 \mathrm{a}$ \\
\hline & & Pyrimethanil & $0 \mathrm{~b}$ & $0 \mathrm{~b}$ \\
\hline & & Fludioxonil & $0 \mathrm{~b}$ & $0 \mathrm{~b}$ \\
\hline \multirow[t]{3}{*}{ CLX8692 } & 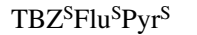 & Nontreated & $93 \mathrm{a}$ & $31.1 \mathrm{a}$ \\
\hline & & Pyrimethanil & $0 \mathrm{~b}$ & $0 \mathrm{~b}$ \\
\hline & & Fludioxonil & $0 \mathrm{~b}$ & $0 \mathrm{~b}$ \\
\hline
\end{tabular}

${ }^{\mathrm{x}}$ Data were pooled from the two experimental runs because there were no significant interactions between run and variables; values within the same column for each isolate followed by the same letter are not significantly different according to the Waller-Duncan K-ratio $t$ test at $\mathrm{K}$ ratio $=100$ $(P=0.05)$. Disease incidence data were arcsine-transformed prior to analysis.

y $\mathrm{TBZ}=$ thiabendazole, $\mathrm{Flu}=$ fludioxonil, $\mathrm{Pyr}=$ pyrimethanil, $\mathrm{R}=$ resistant, $\mathrm{S}=$ sensitive, $\mathrm{LR}=$ low resistance, $\mathrm{MR}=$ moderate resistance, $\mathrm{HR}=$ high resistance.

${ }^{\mathrm{z}}$ Nontreated, pyrimethanil, and fludioxonil were applied as sterilized water, Penbotec $400 \mathrm{SC}$ at $1.25 \mathrm{ml} / \mathrm{liter}$, and Scholar $230 \mathrm{SC}$ at $0.94 \mathrm{ml} / \mathrm{liter}$, respectively. from decayed fruit from five packinghouses in 2010 and 2011, respectively (Table 1). In 2010,84.7 and 7\% of the isolates from packinghouses $\mathrm{A}$ and $\mathrm{B}$, respectively, were resistant to pyrimethanil, and no pyrimethanil-resistant isolates were found at the three other packinghouses (Table 1). At packinghouse A, the apple fruit from the 2010 crop were drenched with either pyrimethanil or fludioxonil; decayed fruit samples were collected in 2011 from both treatments after several months of storage, and $95.8 \%$ of the isolates from the fruit treated with pyrimethanil were resistant to pyrimethanil whereas only $4.2 \%$ of the isolates from the fruit treated with fludioxonil were resistant to pyrimethanil. At packinghouse $\mathrm{B}$, the frequency of pyrimethanil resistance was reduced from $7 \%$ of the isolates collected in 2010 to $1 \%$ among the isolates collected in 2011, when the postharvest drench treatment was switched from pyrimethanil to fludioxonil. In 2010, no pyrimethanil-resistant isolates were detected at packinghouses $\mathrm{C}, \mathrm{D}$, and E. In 2011, 1.8\% of the isolates collected from packinghouse $\mathrm{C}$ were resistant to pyrimethanil and no pyrimethanil-resistant isolates were detected at packinghouses D and E (Table 1).

In both years, TBZ-resistant isolates were detected at all packinghouses but the frequency varied (Table 1). At packinghouse A, $85.9 \%$ of the isolates collected in 2010 were resistant to TBZ, and the frequency of TBZ resistance was reduced to $12.8 \%$ in 2011 , when fludioxonil was used on the 2010 crop but increased to $97.4 \%$ in 2011 , when pyrimethanil continued to be used on the 2010 crop. The frequency of TBZ-resistant isolates was reduced from $55.2 \%$ in 2010 to $3.2 \%$ in 2011 at packinghouse D and slightly reduced at packinghouses $\mathrm{B}, \mathrm{C}$, and $\mathrm{E}$ (Table 1). No fludioxonil-resistant isolates were detected in 2010 or 2011.

At packinghouses $\mathrm{A}$ and $\mathrm{B}$, where pyrimethanil had been used yearly as a postharvest drench treatment for 4 to 5 years, $93.5 \%$ $(275 / 294)$ of the TBZ-resistant isolates were resistant to pyrimethanil whereas no TBZ-sensitive isolate $(0 / 276)$ was resistant to pyrimethanil (Table 3); however, one pyrimethanil-resistant isolate from packinghouse $\mathrm{C}$ was sensitive to TBZ (Table 1).

Phenotypes of pyrimethanil-resistant isolates. Based on the inhibitory effects of different concentrations of fungicides on conidial germination, three pyrimethanil-resistant phenotypes were identified. Most isolates were classified as having either high resistance or low resistance to pyrimethanil (Fig. 1). Of the 159 pyrimethanil-resistant isolates collected in $2010,52.2,3.8$, and $44 \%$ were classified as having low, moderate, and high resistance, respectively. Of the 117 pyrimethanil-resistant isolates collected in 2011, 36.7, 5.1, and 58.1\% were classified as having low, moderate, and high resistance, respectively.

Efficacy of postharvest fungicides in controlling blue mold caused by different fungicide-resistant phenotypes. Fludioxonil was effective in controlling blue mold incited by pyrimethanilresistant isolates that were either sensitive or resistant to TBZ. Pyrimethanil completely controlled blue mold caused by pyrimethanil-sensitive isolates regardless of their sensitivity to TBZ (Table 2). Pyrimethanil failed to provide satisfactory control of blue mold incited by isolates with high or moderate resistance to pyrimethanil but it partially controlled blue mold caused by isolates with low pyrimethanil resistance, reducing the decay incidence from 95 to $67 \%$ in comparison with the nontreated control.

Table 3. Correlation between thiabendazole (TBZ) resistance and pyrimethanil (Pyr) resistance in Penicillium expansum isolates from apple fruit $^{z}$

\begin{tabular}{lccc}
\hline & \multicolumn{2}{c}{ Phenotypes } & \\
\cline { 2 - 3 } Phenotypes & Pyr-resistant & Pyr-sensitive & $\boldsymbol{N}$ \\
\hline TBZ-resistant & 275 & 19 & 294 \\
TBZ-sensitive & 0 & 276 & 276 \\
\hline
\end{tabular}

${ }^{\mathrm{z}}$ Data were combined from 2010 and 2011 samples from two packinghouses where pyrimethanil had been used yearly as a postharvest drench for 4 to 5 years. A $\chi^{2}$ test indicated that a significant higher percentage of TBZ-resistant isolates than of TBZ-sensitive isolates developed pyrimethanil resistance $(P<0.0001) . N=$ total number of isolates. 


\section{Discussion}

In this study, we documented that a high frequency of pyrimethanil resistance developed in $P$. expansum at a packinghouse after pyrimethanil had been used annually for five consecutive years as a postharvest drench on apple fruit. We identified three phenotypes of pyrimethanil resistance in $P$. expansum and documented that pyrimethanil at label rate failed to control blue mold incited by isolates with high or moderate resistance to pyrimethanil. Currently, pyrimethanil along with fludioxonil are the two key postharvest fungicides available as alternatives to TBZ for use on apple in the United States To retain the effectiveness of these fungicides, practices to manage fungicide resistance in $P$. expansum should be implemented.

Pyrimethanil resistance was first detected in $P$. expansum from decayed apple fruit from packinghouse B in 2009 (22). After this initial finding, recommendations on the rotation of postharvest fungicides for drench treatments were made to apple packers. Pyrimethanil was applied as a prestorage drench treatment to the fruit after harvest in 2009 at all five packinghouses. At packinghouses A and B, pyrimethanil had been used as a postharvest drench for the past five consecutive seasons (since 2005) whereas, at the three other packinghouses, pyrimethanil had not been used before 2009. At both packinghouses A and B, the frequency of pyrimethanil resistance was notably reduced when fludioxonil instead of pyrimethanil was used on the 2010 crop. At packinghouse A, some apple fruit from the 2010 crop continued to be treated with pyrimethanil, and the frequency of pyrimethanil resistance among the isolates collected in 2011 increased. These results suggest that repeated annual use of pyrimethanil as a postharvest drench can lead to the development of pyrimethanil resistance in $P$. expansum and that a fungicide rotation with fludioxonil was effective in reducing pyrimethanil-resistant populations.

In the present study, we did not recover isolates exhibiting resistance to fludioxonil in $P$. expansum from decayed apple fruit. This may be due to the fact that fludioxonil had not been widely used before 2010 at the packinghouses where decayed fruit were collected. In addition, a previous study indicated that there are fitness costs associated with fludioxonil-resistant mutants generated by UV mutagenesis in the laboratory (13). Fitness costs may lead to the disadvantages for fludioxonil-resistant strains in competing with wild-type strains. Fludioxonil is considered a low- to medium-risk fungicide for the development of resistance in fungal pathogens (6). However, because $P$. expansum is at high risk for development of fungicide resistance (2), monitoring of fludioxonil resistance is needed because this fungicide is now increasingly used by apple packers.

In this study, pyrimethanil-resistant isolates were all sensitive to fludioxonil. This is consistent with the results of Li and Xiao (12), who reported that, in the baseline population of $P$. expansum from apple in Washington, all isolates were sensitive to fludioxonil and pyrimethanil. However, the results of the present study differ from those of a previous study (13) reporting that laboratory UVinduced pyrimethanil-resistant mutants exhibited a low level of resistance to fludioxonil, though fludioxonil-resistant mutants were sensitive to pyrimethanil. The differences in the selection process for resistant mutants in the lab and resistant isolates in the field (packinghouse) may explain the discrepancy in the results between the two studies. The lack of resistance to fludioxonil in pyrimethanil-resistant isolates of $P$. expansum further supports the use of fludioxonil as a rotation fungicide to control pyrimethanil-resistant isolates.

All pyrimethanil-resistant isolates except one also were resistant to TBZ but there was no cross resistance between the two fungicides because isolates that were resistant to TBZ but sensitive to pyrimethanil also were observed in the present study. TBZ had been used for many years at these packinghouses and it is likely that TBZ resistance was already present in the $P$. expansum populations at these packinghouses when the new postharvest fungicides pyrimethanil and fludioxonil were introduced. The high correlation between TBZ resistance and pyrimethanil resistance in the absence of cross resistance between the two fungicides suggests that TBZ resistance may have accelerated the adaptation of TBZ-resistant strains to pyrimethanil, leading to the development of strains resistant to both. Such a phenomenon has been reported previously in other fungal pathogens. Field isolates of $V$. inaequalis already resistant to the fungicide dodine have shown accelerated adaptation to demethylation inhibitor (DMI) and benzimidazole fungicides (8). A laboratory study has shown that Monilinia fructicola isolates resistant to DMI fungicides are prone to accelerated adaptation to azoxystrobin (14). The underlying mechanisms for the correlation between TBZ resistance and the development of pyrimethanil resistance in $P$. expansum are unknown.

In this study, the three phenotypes of pyrimethanil resistance were identified based on the level of resistance. It appeared that the population of $P$. expansum exhibited a great range of resistance to pyrimethanil. Similar findings have also been reported in $\mathrm{B}$. $\mathrm{ci}$ nerea. Three anilinopyrimidine-resistant phenotypes with levels of resistance varying from low to very high were identified in field populations of $B$. cinerea in French vineyards, and two of the three phenotypes are multidrug resistance phenotypes, exhibiting resistance to other, chemically unrelated fungicides phenylpyrroles or dicarboximides (10). The molecular mechanisms of pyrimethanil resistance in fungal pathogens are currently not fully understood $(5,10)$. The existence of phenotypes with varying levels of resistance to pyrimethanil may also suggest that different molecular mechanisms may be involved in pyrimethanil resistance in $P$. expansum. The pyrimethanil-resistant populations in 2010 and 2011 were dominated by the high- and low-resistant phenotypes but it remains to be determined whether the low-resistant populations would move toward high resistance if pyrimethanil were used repeatedly on an annual basis at these packinghouses. Future research is needed to determine resistance stability in the absence of the fungicide, fitness, and competitive ability of pyrimethanilresistant phenotypes of $P$. expansum because these biological and ecological characteristics are important to the development and implementation of fungicide resistance management programs.

Pyrimethanil failed to control blue mold incited by the highresistance phenotype, indicating that the presence of the highresistance phenotype could lead to practical resistance: failure of disease control. In fact, at packinghouse A, a notable high decay incidence was evident among the fruit while decayed fruit samples were being collected. It appeared that fludioxonil was an effective fungicide that can be rotated with pyrimethanil because such a rotation program reduced pyrimethanil-resistant populations and fludioxonil was effective to control blue mold incited by pyrimethanil-resistant strains of $P$. expansum.

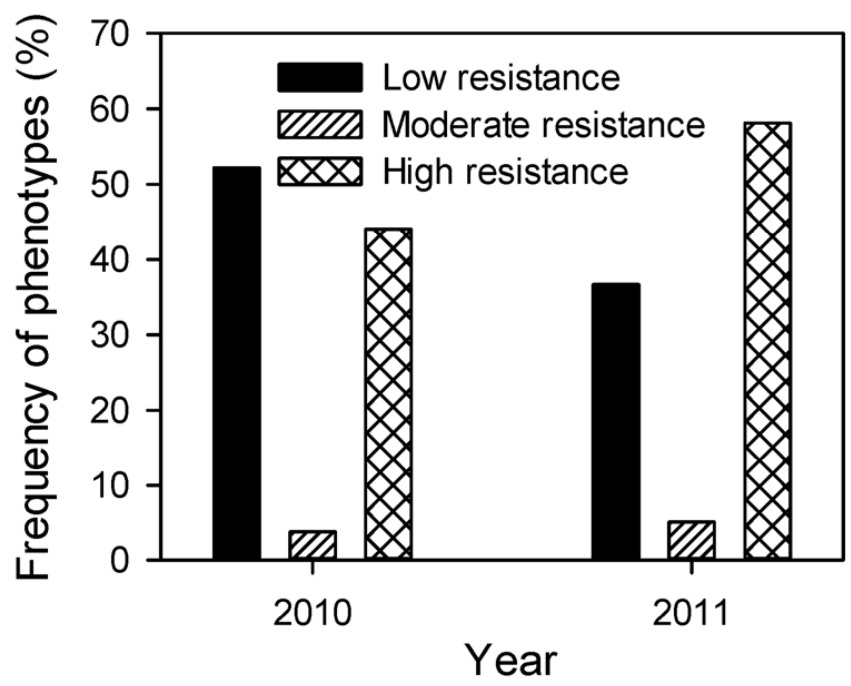

Fig. 1. Frequency of pyrimethanil-resistant phenotypes of Penicillium expansum collected from decayed apple fruit in 2010 and 2011. 


\section{Acknowledgments}

This research was supported, in part, by the Washington Tree Fruit Research Commission. We thank R. Boal for technical assistance.

\section{Literature Cited}

1. Amiri, A., Heath, S. M., and Peres, N. A. 2013. Phenotypic characterization of multifungicide resistance in Botrytis cinerea isolates from strawberry fields in Florida. Plant Dis. 97:393-401.

2. Brent, K. J., and Hollomon, D. W. 1998. Fungicide resistance: the assessment of risk. FRAC Monogr. No.2, Brussels.

3. Eckert, J. W., and Ogawa, J. M. 1988. The chemical control of postharvest diseases: deciduous fruits, berries, vegetables and root/tuber crops. Annu. Rev. Phytopathol. 26:433-469.

4. Errampalli, D., Brubacher, N. R., and DeEll, J. R. 2006. Sensitivity of Penicillium expansum to diphenylamine and thiabendazole and postharvest control of blue mold with fludioxonil in 'McIntosh' apples. Postharvest Biol. Technol. 39:101-107.

5. Fritz, R., Lanen, C., Colas, V., and Leroux, P. 1997. Inhibition of methionine biosynthesis in Botrytis cinerea by the anilinopyrimidine fungicide pyrimethanil. Pestic. Sci. 49:40-46.

6. Fungicide Resistance Action Committee. 2013. FRAC Code List 2013: fungicides sorted by mode of action (including FRAC code numbering). http://www.frac.info/publication/anhang/FRAC\%20Code\%20List\%202013update\%20April-2013.pdf

7. Gomez, K. A., and Gomez, A. A. 1984. Statistical Procedures for Agricultural Research, 2nd ed. John Wiley and Sons, New York.

8. Koeller, W., and Wilcox, W. F. 2001. Evidence for the predisposition of fungicide-resistant isolates of Venturia inaequalis to a preferential selection for resistance to other fungicides. Phytopathology 91:776-781.

9. Leroux, P., Chapeland, F., Desbrosses, D., and Gredt, M. 1999. Patterns of cross-resistance to fungicides in Botryotinia fuckeliana (Botrytis cinerea) isolates from French vineyards. Crop Prot. 18:687-697.

10. Leroux, P., Frita, R., Debiu, D., Albertini, C., Lanen, C., Bach, J., Gredt, M., and Chapeland, F. 2002. Mechanisms of resistance to fungicides in field strains of Botrytis cinerea. Pest Manage. Sci. 58:876-888.

11. Leroux, P., and Gredt, M. 1996. In vitro methods for monitoring pyrime- thanil resistance of Botrytis cinerea in grapevine. Bull. OEPP/EPPO Bull. 26:186-188.

12. Li, H. X., and Xiao, C. L. 2008. Baseline sensitivities to fludioxonil and pyrimethanil in Penicillium expansum populations from apple in Washington State. Postharvest Biol. Technol. 47:239-245.

13. Li, H. X., and Xiao, C. L. 2008. Characterization of fludioxonil-resistan and pyrimethanil-resistant phenotypes of Penicillium expansum from apple. Phytopathology 98:427-435.

14. Luo, C.-X., and Schnabel, G. 2008. Adaptation to fungicides in Monilinia fructicola isolates with different fungicide resistance phenotypes. Phytopathology 98:230-238.

15. Myresiotis, C. K., Karaoglanidia, G. S., and Tzavella-Klonari, K. 2007. Resistance of Botrytis cinerea isolates from vegetable crops to anilinopyrimidine, phenylpyrrole, hydroxyanilide, benzimidazole, and dicarboximide fungicides. Plant Dis. 91:407-413.

16. Pitt J. I. 2002. A Laboratory Guide to Common Penicillium Species. Food Science Australia, North Ryde, NSW, Australia.

17. Rosenberger, D. A. 2014. Blue mold. Pages 76-77 in: Compendium of Apple and Pear Diseases and Pests, 2nd ed. T. B. Sutton, H. S. Aldwinckle, A. M. Agnello, and J. F. Walgenbach, eds. American Phytopathological Society, St. Paul, MN

18. Rosenberger, D. A., Wicklow, D. T., Korjagin, V. A., and Rondinaro, S. M 1991. Pathogenicity and benzimidazole resistance to Penicillium species recovered from flotation tanks in apple packinghouses. Plant Dis. 75:712-715.

19. Sholberg, P. L., Bedford, K., and Stokes, S. 2005. Sensitivity of Penicillium spp. and Botrytis cinerea to pyrimethanil and its control of blue and grey mold of stored apples. Crop Prot. 24:127-134.

20. Spotts, R. A., and Cervants, L. A. 1993. Filtration to remove spores of Penicillium expansum from water in pome fruit packinghouses. Tree Fruit Postharvest J. 4:16-18.

21. Xiao, C. L., and Kim, Y. K. 2010. Control of postharvest diseases in apples with reduced-risk fungicides. Stewart Postharvest Review. Online publication. doi:10.2212/spr.2010.1.6

22. Xiao, C. L., Kim, Y. K., and Boal R. J. 2011. First report of occurrence of pyrimethanil resistance in Penicillium expansum from stored apples in Washington State. Plant Dis. 95:72. 